\title{
Research Status of Ventilation Method in Welding Workshop
}

\author{
Shijia Chen
}

North China Electricity Power University, Department of Power Engineering, China, Hebei, Baoding, 071000

2280309421@qq.com

Keywords: Welding workshop; Flue gas treatment; Ventilation method; Flue gas hazards; Air purification

\begin{abstract}
It shows the research status of ventilation and dust removal method in welding workshop at home and abroad by simply explaining the diffusion principle of welding flue gas and the particle size distribution of welding dust. Moreover, it analyses the formation, components and perniciousness of the welding dust, and demonstrates the seriousness of the problem of welding dust pollution in China. Besides, it introduces a number of commonly used ventilation method and detailed operation of the system, roughly analyses the distinction and contact between different ventilation methods and systems, and gives specific recommendations for actual situation. As is to say, it provides a reference for different welding requirements to choose reasonable airflow distribution. To conclude, it summarizes various flue gas treatment methods at home and abroad, and finds that the treatment of flue gas needs to be matched with the welding process. Moreover, it also need to take consideration to the energy consumption, efficiency, economy, practicality and other factors even could take a variety of ways to use when necessary.
\end{abstract}

\section{Introduction}

Welding is an advanced manufacturing method of modern manufacturing, which is widely used by mechanical processing industry. However, in the process of welding, it will produce a lot of welding dust and harmful gases, which pollutes the working environment and seriously endangers the health of workers. With the industrialization process in China, the scale of the welding workshop is enlarging while the hazards of welding dust are also increasingly prominent, which has become the focus of the industry's problems ${ }^{[1]}$. Reasonable airflow organization has a vital role in the indoor air quality of the welding workshop. As a consequence, according to different requirements to choose a reasonable ventilation method is conducive to discharge indoor flue gas, keeping the air of the work area of clean.

\section{Production and Diffusion of Welding Dust}

In the process of welding, the welding material in the welding arc under high temperature $\left(4000{ }^{\circ} \mathrm{C} \sim 6000{ }^{\circ} \mathrm{C}\right.$ ) evaporated into metal vapor, and rapidly oxidized in the air, condensed into $100 \sim 10-2 \mu \mathrm{m}$ particles. At the same time, it also produces some harmful gases such as $\mathrm{CO} 2, \mathrm{NO} 2$, NO3 and so on ${ }^{[2]}$.

Welding dust is generated at the high temperature of the arc. Simultaneously, it makes the gas around the arc expands and carries smoke particles rising in the form of aerosol floating in the operating environment. The dust is composed of continuous isolated flames, and due to the constant involvement of the surrounding gas and the impact of the arc when it rising, it will form a variety of whirlpool movement that is turbulence. At the initial stage the speed of diffusion is faster, however, with the constant involvement of the surrounding gas and the decrease of the dust temperature so that the aerosol dust density increases, the speed of diffusion gradually decays. After rising to a certain height, the aerosol smoke begins to drop, when the falling dust and rising dust interact. Therefore, it will form a stable welding dust concentration zone within a certain height ${ }^{[3]}$. 


\section{The Particle Size of Welding Dust}

The typical acid-base welding dust composition and particle size are as follows: Table 1 Typical particle size distribution of acid-base welding dust [\%]

\begin{tabular}{llllll}
\hline $\begin{array}{l}\text { Electrode } \\
\text { model }\end{array}$ & $\leq 2 \mu \mathrm{m}$ & $2 \mu \mathrm{m} \sim 4 \mu \mathrm{m}$ & $4 \mu \mathrm{m} \sim 6 \mu \mathrm{m}$ & $6 \mu \mathrm{m} \sim 10 \mu \mathrm{m}$ & $\geq 10 \mu \mathrm{m}$ \\
\hline J507 & 81.5 & 12.0 & 4.5 & 1.5 & 0.5 \\
$\mathrm{~J} 422$ & 73.5 & 18.5 & 5.5 & 1.5 & 1.0 \\
\hline
\end{tabular}

The size of welding dust is generally below $1 \mu \mathrm{m}$. The study shows that less than $1 \mu \mathrm{m}$ particles will penetrate into the depths of the lungs, which do greater harm to the human body. At present, in various types of industrial and mining enterprises, the total number of welding workers is about 10 million and the total number of pneumoconiosis patients more than 500,000 (except for suspected pneumoconiosis), ranking first in the world, which has become a more prominent issue of labor safety and health work in China ${ }^{[5]}$.

\section{Ventilation method}

How to solve the pollution of welding dust is the main problem which each country faced to. Building a good welding environment plays a decisive role in improving labor productivity.

Ventilation can be divided into general ventilation system, local ventilation system and blow-suction ventilation system.

General Ventilation. General ventilation is a method that dilutes the entire area of welting workshop containing welding dust with fresh air, and continuously remove contaminated air. General ventilation due to its principle is also known as dilution ventilation. According to the ventilation power, it is divided into natural ventilation and mechanical ventilation ${ }^{[7]}$.

(1) Natural Ventilation. Set the exhaust sunroof or natural ventilation devices on the roof and windows and doors at the lower part of the external walls. It also needs adequate ventilation area and air volume adjustment device. Natural ventilation utilizes the difference of heat pressure in workshop and outdoor wind pressure to ventilate. But the natural ventilation is affected by the outdoor climate. Because of the difference in natural inlet efficiency, the location and elevation of natural ventilation devices have a greater impact on welding dust controlling.

(2) Mechanical Ventilation. It is a method that removes the smoke out of the workshop by the fan installed on the wall and ceiling or recycles the smoke after purification by the purifier, to achieve the purpose of reducing the concentration of dust in the workshop. The air flow organization has the following several ways:

(a)Upstream approach: Supply the air at bottom, exhaust in the upper. This way is conducive to the exclusion of flue gas consistent with the rising direction of welding fumes. The disadvantage of the ascending flow is that the flue gas has passed the welder's breathing zone during the rising process and has some pollution to the working environment. The air flow of the door and window, the flow of people, the logistics and the operation of the vehicle all affect its ventilation.

(b)Horizontal flow mode: From the workshop side of the external wall of the mechanical air supply, the other side of the mechanical exhaust. For multi-span large workshop, relay induction fan is also installed in the middle span. This approach requires the heavily polluted ministry to be placed on the downwind side, at the same time the outdoor wind direction affects its ventilation effect; with this method, both the number of fans and the energy consumption are large.

(c)Ejector: Increase the jet fan on the basis of mechanical ventilation. The principle is that the high-speed jet on both sides injects a small amount of air to induct and stir a lot of surrounding air, and to lead to the target specific direction finally to the outside row. This method can solve the problem of welding fume concentration in the workshop and the ventilation efficiency is high, but the one-time investment is larger.

For the welding dust treatment of the whole workshop, the latest dust removal method is 
displacement ventilation. Displacement ventilation sends the fresh air into the working area at low wind speed, according to the principle of extrusion to promote fresh air pollution air to the upper part of the exhaust. The air supply mode compared with the traditional mixing ventilation, can not only regulate the air humidity and temperature of work area effectively, but also remove the gas containing welding dust through air movement. Therefore, the temperature and humidity in workshop can be adjusted to the required range and the air in the human work area is purified ${ }^{[8]}$.

Local Ventilation System. Local ventilation is to capture the flue gas directly from the welding point, and then discharged outdoors by purification. Domestic and foreign local ventilation equipment mainly includes the following forms:

(1) Vacuuming with Gun Cleaner. Vacuum gun uses high negative pressure welding cleaner with welding gun type suction nozzle. The suction nozzle is coaxially mounted with the torch, and immediately capture in the distance from the nearest place where welding so that the welder can move to any place ${ }^{[9]}$. This method is a kind of welding fume capture method, which are the most commonly used in welding robot and automatic welding.

(2) Vacuuming with Hand-held Mask. The operator can capture the welding fume produced by the welding point directly with the vacuum mask to achieve efficient dust removal effect. The mask has the advantages of convenience, flexibility and good mobility, and is especially suitable for welding dust removal of large workpieces and large components ${ }^{[10]}$.

\section{Conclusion}

There are many ways to treat the welding dust in the welding workshop. The treatment of the welding dust must be matched with the welding process. For the different welding products and welding technology, effective ventilation, purification and reasonable airflow organization design can effectively control the diffusion of the welding smoke, and solve the problem of pollution in the work area. For different concentrations of welding dust, the design can choose one or more of the ventilation method of joint method.

When choosing ventilation, the factors such as energy consumption, efficiency, and investment should be taken consideration to.

\section{References}

[1] Jun Liu, Zonglin Wang, Li Gu. Automobile factory welding workshop welding smoke treatment and energy saving, HVAC 2008 Volume 42 No. 4

[2] Aiming Niu, Zhenjiang Li, Ying Qiao. High industrial plant control of the comparison of ventilation ventilation, energy saving, 2006 eighth issue

[3] Jiazhen Zhang. Welding plant dust characteristics and control measures, industrial safety and environmental protection, 2006 No. 32 No. 3

[4] Qing Li, Lina Jiang. Welding workshop ventilation method, public works design, 1007-9467 (2010) 06-0070-05

[5] Huaijiang Zheng. Welding workshop control flue gas technical measures, experience reference, 1002-2333 (2007) 09-0153-03

[6] Weimin Zhu, Mingbao Li, Hongwei Tan, Qizhi Ke. Study on Ventilation Mode of Welding Workshop in Shipyard [J]. HVAC, 2008, (02):18-21+100.

[7] Qiuxin Liu, Chuanhui Zhou, Xiaoguo Sun. Study on Ventilation Mode of Welding Workshop in Automobile Factory [J]. Industrial Safety and Environmental Protection, 2005, (03):17-19.

[8] Ke Yang, Qiangmin Li. Energy saving ventilation of closed welding workshop [J]. Shanghai Energy Conservation, 2008, (01):43-46.

[9] Haibo Sun. Study on the Control and Displacement Ventilation and Air Conditioning 
Technology of Welding Industry [J]; Journal of Hunan University of Technology (Natural Science Edition), 2010.

[10] Fei Ye, Gang Liu, Fengchang Yang. Study on the Influence of Ventilation Mode on Concentration Field in Welding Workshop [J]. Building Thermal Energy Ventilation and Air Conditioning, 2014, (04): 78-80. 